\title{
Pembangunan Sistem Informasi Manajemen Rantai Pasok Menggunakan Metode Min-Max Untuk Pengendalian Stok Bahan Baku Pada CV. Bidara Karya Gemilang
}

\author{
Hadi Apryana $S R^{1}$, Tacbir Hendro Pudjiantoro ${ }^{2}$, Asep Id Hadiana ${ }^{3}$ \\ 1,2,3 Jurusan Informatika, FSI, Universitas Jenderal Achmad Yani, Cimahi, Indonesia \\ e-mail: hadiapryana@gmail.com ${ }^{1}$, tacbirpudjiantoro@gmail.com², asep.hadiana@lecture.unjani.ac.id ${ }^{3}$
}

\section{INFORMASI ARTIKEL}

Sejarah Artikel:

Diterima Redaksi : 25 Mei 2020

Revisi Akhir : 25 Juli 2020

Diterbitkan Online : 06 Agustus 2020

\section{Kata Kunci :}

Bahan baku, Supply Chain Management, Min-Max

\section{Korespondensi :}

Telepon / Hp : +62 85321146734

E-mail : hadiapryana@gmail.com

\section{A B S T R A K}

CV. Bidara Karya Gemilang adalah perusahaan bergerak di bidang manufaktur yang memproduksi pakaian jadi untuk dijual dan menerima order pesanan dalam pembuatan baju dalam partai besar ataupun kecil. Dalam pengelolaan bahan baku yang terjadi mengalami perbedaan antara pembukuan dengan bahan baku yang ada di lapangan sehingga dapat mengakibatkan terhambatnya proses produksi terhadap order pesanan, serta bertambahnya beban proses produksi yang tinggi menyebabkan kesulitan dalam mengontrol proses produksi yang sedang berjalan karena setiap divisi sering telambat dalam memberikan informasi. Dengan menggunkan konsep Supply Chain Management diharapkan dapat Mengolah data order pesanan, memberikan informasi bahan-baku yang akurat, dan perencanaan produksi yang tepat, dengan memanfaatkan 2 tahapan scm yaitu midstream dan downstream. Metode Min-Max juga diharapkan dapat membantu untuk mengetahui batas maximum dan minimum bahan baku produksi dengan melakukan perhitungan pada periode tertentu sesuai dengan kebutuhan perusahaan. Pada penelitian ini metode pengembangan perangkat lunak yang digunakan ini yakni waterfall untuk menghasilkan aplikasi yang lebih berkualitas. Hasil penelitian ini berupa sistem yang dapat memberikan informasi seputar order pesanan, batas maximum dan minimum bahan baku, penjadwalan produksi, dan laporan produksi yang berupa hasil produksi

\section{PENDAHULUAN}

CV. Bidara Karya Gemilang merupakan salah satu perusahaan manufaktur yang bergerak dibidang usaha produksi pakaian jadi. Dalam pengelolaan bahan baku yang terjadi sering mengalami perbedaan antara pembukuan dengan bahan baku yang ada di produksi sehingga dapat mengakibatkan terhambatnya proses produksi terhadap order pesanan pelanggan. Bahan baku yang dibutuhkan produksi merupakan hal yang perlu diperhatikan untuk menjamin kelancaran produksi [1].

Manajemen Rantai Pasok adalah salah satu konsep untuk meningkatkan produktivitas perusahaan terhadap rantai suplai melalui optimalisasi waktu, aliran informasi terhadap proses produksi dan informasi ketersediaan bahan baku. Supply chain management diharapkan dapat memenuhi kepuasan pelanggan [2], [3], [4].

Menurut [5] manajemen rantai pasokan memiliki pengaruh positif terhadap kinerja perusahaan. perusahaan harus fokus pada penerapan manajemen rantai pasokan agar dapat mempengaruhi tingakt kinerja perusahaan. serta ada beberapa faktor yang dapat menunjang keberhasilan dalam menerapkan manajamen rantai pasokan ini antara lain faktor eksternal dan internal. Faktor eksterna adalah yang menyangkut pada hubungan dengan perusahaan-perusahaan partner.
Faktor internal adalah yang menyangkut bagian semua dari perusahaan.

Bahan baku merupakan bagian penting untuk menjamin kelancaran produksi. Bahan baku yang tersedia hendaknya mencukupi kebutuhan produksi dan tidak melebihi kapasitas penggunaan produksi setiap bulannya agar tidak terjadi pemborosan dalam melakukan pembelian bahan baku terhadap persediaan bahan baku untuk produksi [6].

Kegagalan dalam mengelola bahan baku ini menyebabkan proses produksi yang sering terhambat dan keinginan konsumen tidak tercapai. Sehingga perusahaan perlu melakukan prosedur dan cara pembelian bahan baku yang baik untuk menunjang kegiatan produksi. Perusahaan harus menentukan jumlah bahan baku yang optimal dengan maksud agar jumlah pembelian dapat mencapai biaya persediaan minimum.

Terdapat metode min-max stock untuk melakukan pengendalian persediaan bahan baku, yang meliputi beberapa tahapan yaitu :

1. Menentukan peresediaan pengaman (Safety Stock). Safety Stock adalah persediaan ekstra untuk menjaga sewaktu-waktu ada tambahan kebutuhan atau keterlambatan kedatangan barang.

2. Menentukan persediaan minimum (Minimum Stock). Minimum Stock adalah jumlah pemakaian 
selama waktu pemesanan berjalan antara pesanan per periode dan pemakaian rata-rata dalam bulan/minggu/hari ditambah dengan safety stock.

3. Menentukan persediaan maximum (Maximum Stock). Maximum Stock adalah jumlah maksimum yang diperbolehkan disimpan dalam persediaan [7].

Berdasarkan pada uraian yang dijelasakan sebelumnya, CV. Bidara Karya gemilang perlu menjaga keakuratan stok bahan baku untuk produksi agar proses produksi tidak terhambat dengan tidak ketersediaan bahan baku yang ada dan ketidak cocokan dalam pembukuan yang ada.

Tujuan yang ingin dicapai dari penelitian ini adalah membangun sebuah perangkat lunak sistem informasi manajamen rantai pasok pada CV. Bidara Karya Gemilang yang diharapkan dapat membantu proses pemesanan, penjadwalan produksi serta pengendalian bahan baku untuk produksi.

\section{METODE PENELITIAN}

Terdapat beberapa metode dalam melakukan penelitian sebagai berikut :

\subsection{Metode waterfall}

Metode pengembangan perangkat lunak model waterfall yang mana pada tahap awal adalah analisa kebutuhan dan bagian akhirnya adalah pemeliharaan namun disini hanya sampai tahap pengujan dikarenakan untuk proses pemeliharaan tidak di lakukan [8], [9]. Contoh model waterfall yang telah dihilangkan bagian pemeliharaannya bisa dilihat pada gambar 1 .

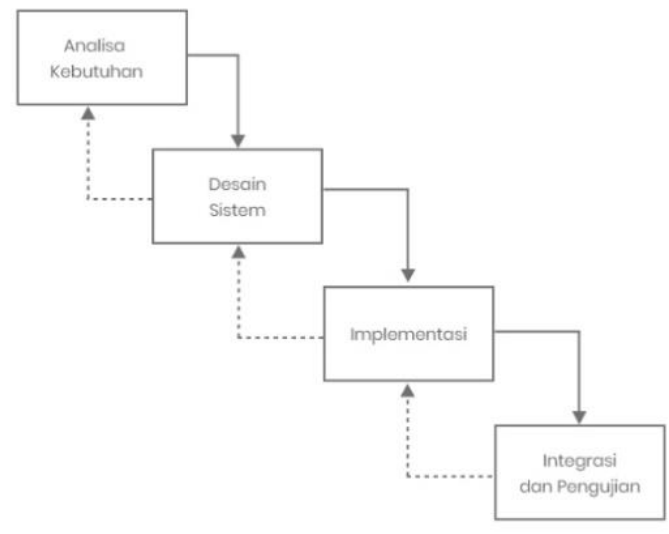

Gambar 1 Metode Waterfall

\subsection{Metode Pengumpulan Data}

Metode pengumpulan data yang dilakukan pada penelitian ini diambil melalui beberapa cara yaitu :

a. Studi Pustaka

Pada tahap ini dilakukan studi pustaka untuk mendapatkan informasi pendukung yang berkaitan dengan penelitian.

b. Observasi

Pada tahap ini dilakukan pengamatan dan pencatatan terkait apa saja yang dibutuhkan sistem serta proses bisnisnya untuk sistem manajemen rantai pasok pada CV.Bidara Karya Gmilang. c. Wawancara

Pada tahap ini melakukan proses penyampaian sejumlah pertanyaan secara tatap muka kepada pihak yang terkait di CV.Bidara Karya Gemilang untuk mendapatkan informasi mengenai komponen-komponen yang dibutuhkan.

\subsection{Metode Min-Max (pengendalian Persediaan)}

Metode min-max sebagai pengendalian persediaan bahan baku untuk menentukan batas safety stock, minimum stock dan maximum stock diharapkan agar tidak terjadi over stock dan out of stock [7], [10]. Penentuan safety stock dilakukan dengan menggunakan rumus sebagai berikut :

Safaty Stock $=($ Pemakaian maksimum - Rata-Rata Kebutuhan) x Lead Time

Penentuan Minimum Stock dilakukan dengan menggunakan rumus sebagai berikut :

Minimum Stock $=($ Rata-Rata Kebutuhan $\mathrm{x}$ Lead time ) + Safety Stock

Penentuan Maximum Stock dilakukan dengan menggunakan rumus sebagai berikut :

Maximum Stock $=2 \mathrm{x}$ (Rata-Rata Kebutuhan $\mathrm{x}$ Lead time ) + Safety Stock

\section{Perhitungan Bahan Baku}

$$
\begin{aligned}
& \text { Safaty Stock }=(3500 \mathrm{yrd}-3000 \mathrm{yrd}) \times 1.75 \\
& =875 \mathrm{yrd} \\
& \text { Minimum Stock }=(3000 \mathrm{yrd} \times 1.75)+875 \\
& =6125 \mathrm{yrd} \\
& \text { Maximum Stock }=2 \times(3000 \mathrm{yrd} \times 1.75)+875 \\
& =12250 \mathrm{yrd}
\end{aligned}
$$

\section{PERANCANGAN SISTEM}

Proses Pembangunan sistem yang dilakukan dalam sistem informasi Manajemen Rantai Pasok ini mengacu pada langkah sebelumnya pada metodologi penelitian. Dimana pada metodologi penelitian disebutkan dalam melakukan pengembangan sistem meliputi tahap analisa kebuthan, desain sistem, implementasi, integrasi dan pengujian.

\subsection{Tahap Analisa Kebutuhan}

Tahapan ini didapatkan dari hasil pengumpulan data yang dijelaskan pada langkah metode penelitian dimana setelah dianalisa menghasilkan sebuah kebutuhan sistem yaitu :Kelola User, Kelola pesanan, Kelola Pelanggan, Kelola Jadwal, Kelola Bahan Baku, Kelola Pembayaran, Kelola Produksi Kelola permintaan oembelian bahan baku. Dimana nantinya setiap role memiliki hak akses yang berbeda - beda dalam mengoperasikan sistem informasi ini, untuk lebih jelasnya lagi dapat dilihat pada use case pada gambar 2 . 


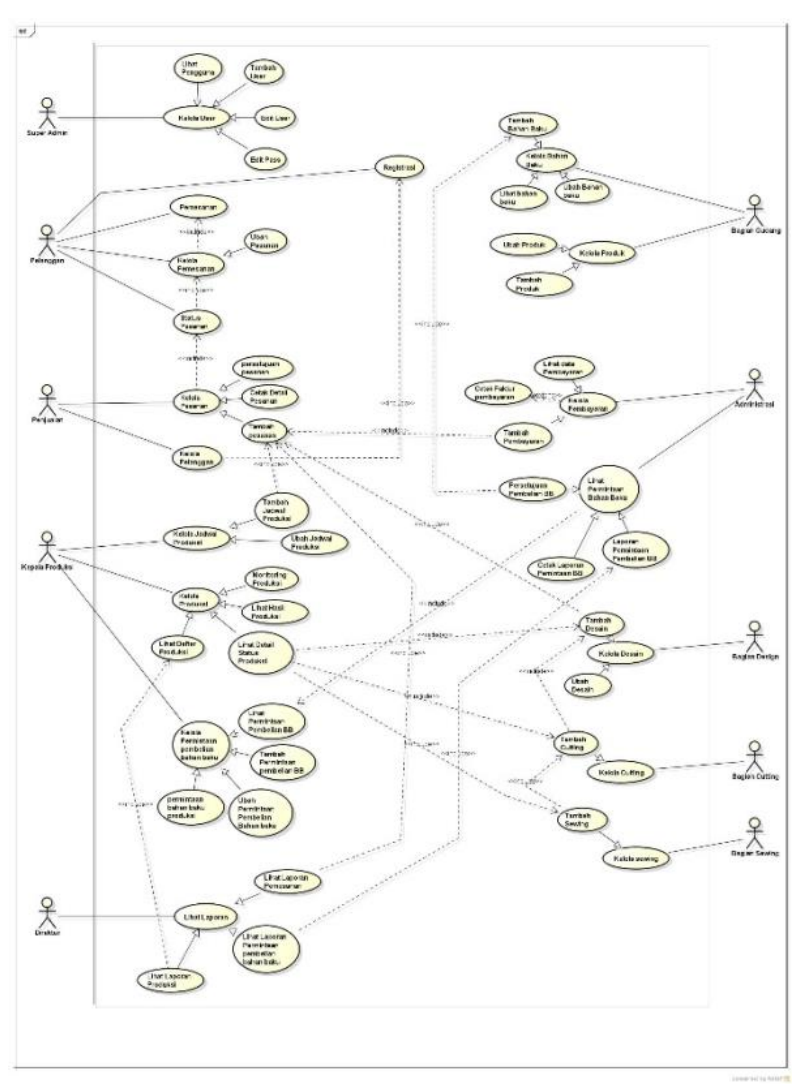

Gambar 2. Use Case Sistem

\subsection{Implementasi}

Tahap implementasi adalah tahap untuk mengimplementasikan dari tahap analisa kebutuhan yang sudah dilakukan. Dimana dalam mengimplementasikannya pada penelitian ini menggunakan framework laravel untuk membuat tampilan website, database MySql.

a. Perancangan Halaman Kelola User

Halaman Kelola User adalah halaman yang hanya dapat diakses oleh super admin saja dimana hak akses super admin dalam sistem ini adalah mengelola semua user yang terlibat di dalam sistem.

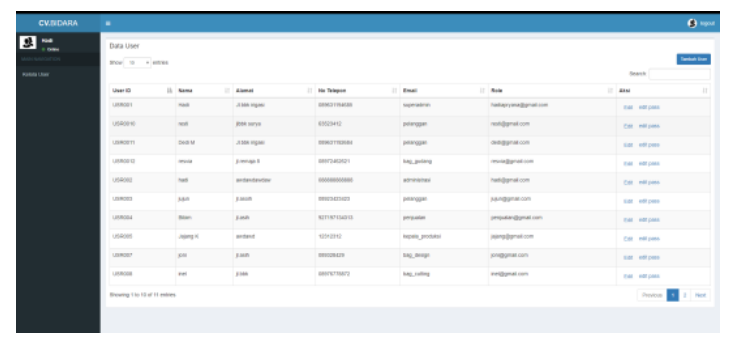

Gambar 4. Halaman Kelola User

b. Perancangan Halaman Kelola Pemesanan

Halaman Kelola Pemesanan adalah halaman yang hanya dapat diakses oleh pelanggan saja dimana hak akses pelanggan dalam sistem ini adalah menambah dan mengubah pesanan.

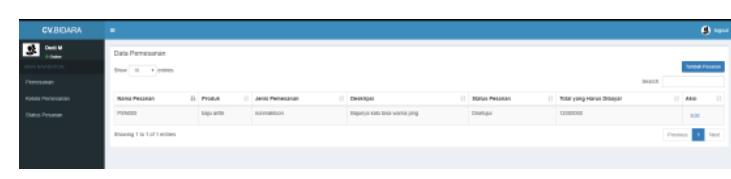

Gambar 5. Halaman kelola Pemesanan

c. Perancangan Halaman Status Pesanan

Halaman Status pesanan adalah halaman yang hanya bisa diakses oleh pelanggan apabila telah melakukan pesanan dan pesanan telah di setujui maka akan memapilkann data status pesanan.

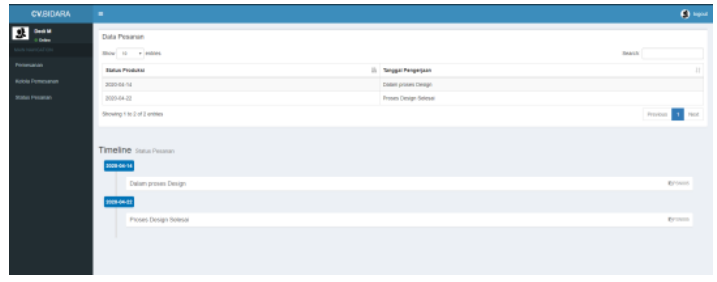

Gambar 6. Halaman Status Pesanan

d. Perancangan Halaman kelola Pesanan

Halaman Kelola pesanan hanya dapat diakses oleh bagian penjualan dan hanya menampilkan data dengan status pesanan belum disetujui oleh bagian penjualan.

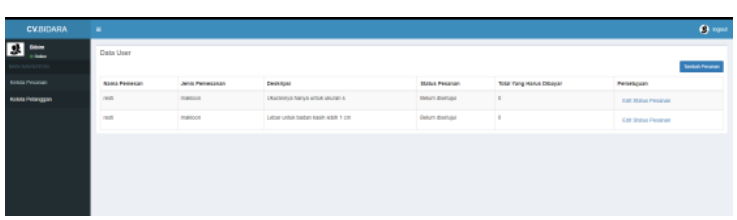

Gambar 7. Halaman kelola Pesanan

e. Perancangan Halaman Kelola Jadwal Produksi

Halaman kelola jadwal hanya dapat diakses oleh bagian kepala produksi , apabila menambah jadwal produksi data hanya menampilkan pesanan yang berstatus disetujui dan belum dijadwalkan.

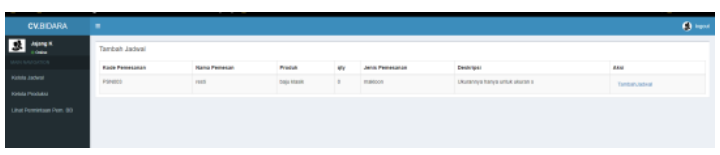

Gambar 8. Halaman Kelola Jadwal Produksi

f. Perancangan Halaman Kelola Produksi

Halaman kelola produksi hanya dapat diakses oleh bagian kepala produksi dan hak akses sistem ini adalah dapat memonitoring serta melihat hasil produk yang sudah berhasil diproduksi. 


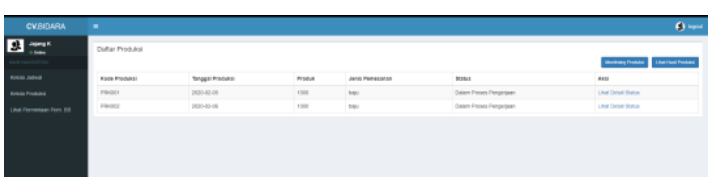

Gambar 9. Halaman Kelola Produksi

g. Perancangan Halaman Kelola Permintaan Pembelian Bahan Baku

Halaman kelola Permintaan Pembelian Bahan Baku ini hanya dapat diakses oleh bagian kepala produksi dalam melakukan permintaan pembelian bahan baku.

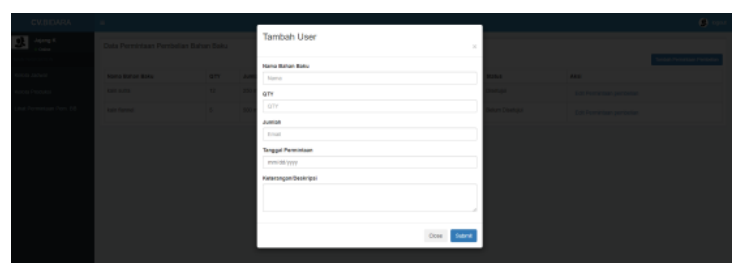

Gambar 10. Halaman Kelola Permintaan Pembelian Bahan Baku

h. Kelola Bahan Baku

Halaman Kelola Bahan baku ini hanya dapat diakses oleh bagian gudang dan memiliki hak akses untuk menambah dan mengubah bahan baku serta akan menampilkan notifikasi apabila bahan baku sudah berada pada jumlah minimum.

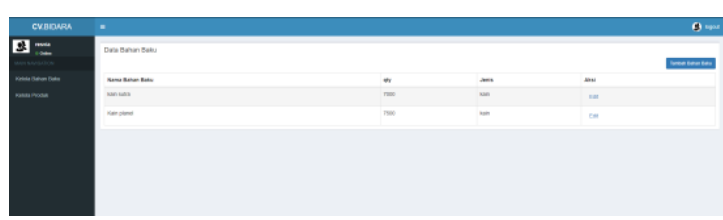

Gambar 11. Halaman Kelola Bahan Baku

i. Perancangan Halaman Kelola Produk

Halaman ini dapat diakses oleh bagian gudang serta mempunyai hak akses untuk menambah dan mengubah produk.

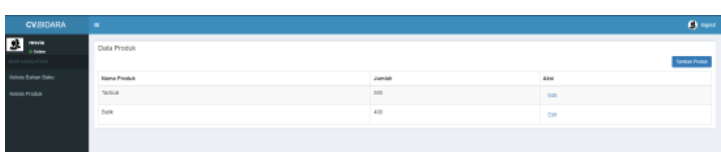

Gambar 12. Halaman Halaman Kelola Produk

j. Perancangan Halaman Kelola Pembayaran

Halaman ini dapat diakses oleh bagian Administrasi untuk menambah pembayaran yang sudah di lakukan oleh pelanggan terhadap pesanan.

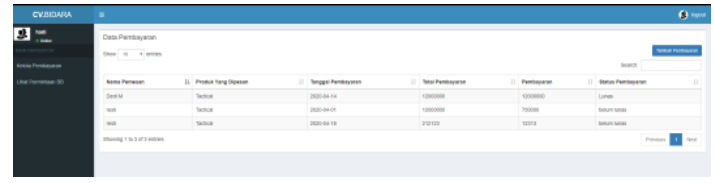

Gambar 13. Halaman Halaman Kelola Pembayaran

k. Perancangan Halaman Kelola Design

Halaman ini dapat diakses oleh bagian design serta mempunyai hak akses untuk menambah dan mengubah design yang telah dibuat yang nantinya akan dapat dilihat oleh pemesan status design yang sudah dilakukan.

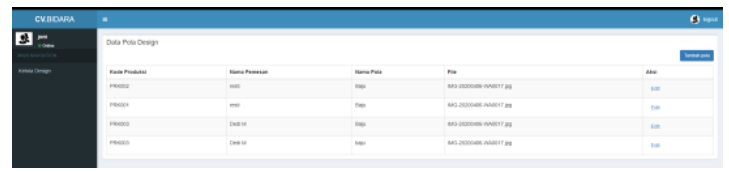

Gambar 14. Halaman Halaman Kelola Design

a. Perancangan Halaman Kelola Cutting

Halaman ini dapat diakses oleh bagian cutting serta mempunyai hak akses untuk menambah cutting yang telah dilakukan yang nantinya akan dapat dilihat oleh pemesan status cutting yang sudah dilakukan.

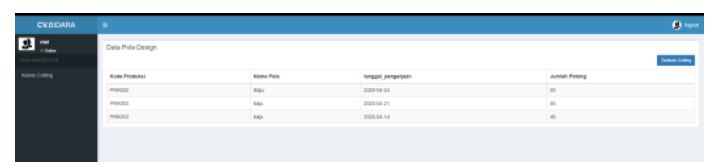

Gambar 15. Halaman Halaman Kelola Cutting

a. Perancangan Halaman Kelola Sewing

Halaman ini dapat diakses oleh bagian sewing serta mempunyai hak akses untuk menambah sewing yang telah dilakukan yang nantinya akan dapat dilihat oleh pemesan status sewing yang sudah dilakukan

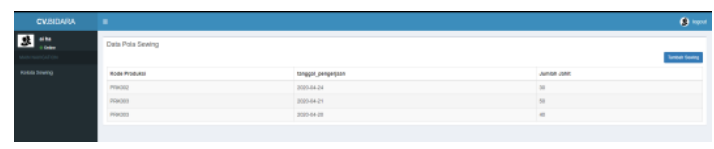

Gambar 16. Halaman Halaman Kelola Sewing 


\section{KESIMPULAN}

Berdasarkan hasil analisa dan pembangunan sistem informasi manajemen rantai paso dengan metode minmax untuk pengendalian persedian pada CV. Bidara ini kesimpulan adalah sebagai berikut :

a. Sistem informasi ini dapat menangani pemesanan yang sdah di lakukan oleh pelanggan dan melihiat status pesanan yang sudah di pesan.

b. Sistem informasi ini dapat membantu jurusan perusahaan dalam mengelola jadwal produksi.

c. Sistem informasi ini dapat membantu perusahaan dalam pengendalaian persediaan bahan baku.

Dengan adanya sistem infromasi manajemen rantai pasok ini maka perusahaan dapat dengan mudah melalukan pengecekan pesanan baru, memonitoring produksi, serta aliran informasi antar bagian dalam produksi akan mudah dilihat dan didapatkan serta notifikasi batas bahan baku minimum dan maximum akan muncul dan memperingati bagian gudang.

\section{DAFTAR PUSTAKA}

[1] A. P. Kinanthi, D. Herlina, and A. Mahardika, "Analisis Pengendalian Persediaan Bahan Baku Menggunakan Metode Min-Max ( Studi Kasus PT . Djitoe Indonesia Tobacco )," vol. 15, no. 2, pp. 87-92, 2016.

[2] S. Anwar, "Manajemen Rantai Pasokan (Supply Chain Management) : Konsep Dan Hakikat," J. Din. Inform., vol. 3, no. 2, pp. 92-98, 2011.

[3] L. Nurhuda, B. Setiawan, and D. R. Andriani, "Analisis Manajemen Rantai Pasok Kentang (Solanum Tuberosum L.) di Desa Ngadas, Kecamatan Poncokusumo, Kabupaten Malang," J. Ekon. Pertan. dan Agribisnis, vol. 1, no. 2, pp. 130-143, 2017.

[4] M.pogoh, "ISSN 2303-1174 M. Pongoh. Analisis Perencanaan Manajemen Rantai Pasok............," Emba, vol. 4, no. 3, pp. 695704, 2016.

[5] L. Rahmasari, "Pengaruh Supply Chain Management Terhadap Kinerja perusahaan dan Keunggulan Bersaing (Studi Kasus pada Industri Kreatif di Provinsi Jawa Tengah)," Maj. Ilm. Inform., vol. 2, no. 3, pp. 89-103, 2011.

[6] E. Ruauw, "Pengendalian Persediaan Bahan Baku (Contoh Pengendalian pada usaha Grenda Bakery Lianli, Manado) Eyverson Ruauw," Ase, vol. 7, no. 1, pp. 1-11, 2011.

[7] C. K. Yedida and M. M. Ulkhaq, "Perencanaan Kebutuhan Persediaan Material Bahan Baku Pada CV Endhigra Prima dengan Metode MinMax," Perenc. Kebutuhan Persediaan Mater. Bahan Baku Pada CV Endhigra Prima dengan Metod. Min-Max, vol. 6, no. 1, 2017.

[8] R. Sastra, "Metode Pengembangan Perangkat Lunak Waterfall Dalam Perancangan Sistem Informasi E-Learning," IJSE - Indones. J. Softw.
Eng. Metod., vol. 3, no. 1, pp. 27-33, 2017.

[9] G. W. Sasmito, "Penerapan Metode Waterfall Pada Desain Sistem Informasi Geografis Industri Kabupaten Tegal," J. Inform. Pengemb. IT, vol. 2, no. 1, pp. 6-12, 2017.

[10] A. Salam and Mujiburrahman, "Pengendalian Persediaan Bahan Baku menggunakan Metode Min- Max Stock pada Perusahaan Konveksi Gober Indo," J. Ekon. dan Manaj. Teknol., vol. 2, no. 1, pp. 47-54, 2018. 